\title{
Treatment outcomes in patients with extranodal marginal zone B-cell lymphoma of the lung
}

Hyun Lee, MD, MS, ${ }^{a}$ Bumhee Yang, MD, MS, ${ }^{b}$ Boda Nam, MD, MS, ${ }^{c}$ Byeong-Ho Jeong, MD, PhD, ${ }^{a}$ Sumin Shin, MD, MS, ${ }^{\mathrm{d}}$ Jae Il Zo, MD, PhD, ${ }^{\mathrm{d}}$ Young Mog Shim, MD, PhD, ${ }^{\mathrm{d}}$ O Jung Kwon, MD, PhD, ${ }^{\mathrm{a}}$ Kyung Soo Lee, $\mathrm{MD}, \mathrm{PhD},{ }^{\mathrm{c}}$ and Hojoong Kim, $\mathrm{MD}, \mathrm{PhD}^{\mathrm{a}}$

\begin{abstract}
Objectives: To evaluate clinical presentations, treatment modalities, and outcomes of pulmonary mucosa-associated lymphoid tissue (MALT) lymphoma by stage strata.

Methods: We retrospectively reviewed 51 patients diagnosed with pulmonary MALT lymphoma between January 2003 and December 2015. To compare treatment modalities and outcomes, we stratified the patients into low-stage (IE/IIE) and high-stage (IIIE/IVE) groups using modified Ann Arbor staging. Progression-free survival was estimated using Kaplan-Meier curves, and differences were compared using the log-rank test. A hazard ratio of progression by stage strata, adjusted for other clinical variables, was determined using a Cox adjusted proportional hazards model.
\end{abstract}

Results: The majority of patients had stage IE disease (76.5\%; 39 of 51). With advancing stage, patients were more likely to have respiratory and B symptoms and higher International Prognostic Index scores. The most common treatment modality was surgical resection in low-stage patients (33 of 43) and chemotherapy in high-stage patients ( 7 of 8). At a median follow-up of 40.7 months, progressionfree survival was longer for low-stage patients (median, 40.7 months vs 24.9 months; $P<.001$ ), and high-stage patients were 9.2 times more likely to progress (hazard ratio, 9.24; $95 \%$ confidence interval, 1.93-44.36). Among 30 patients with surgically resected stage IE disease, 8 with central lesions were treated via lobectomy and 22 with peripheral lesions were treated via lobectomy $(\mathrm{n}=8)$ or limited resection $(n=14)$. One of these patients, with a central lesion, experienced disease recurrence.

Conclusions: Our findings suggest that the clinical course of low-stage pulmonary MALT lymphoma, for which the mainstay of treatment is surgical resection, might be indolent. (J Thorac Cardiovasc Surg 2017;154:342-9)

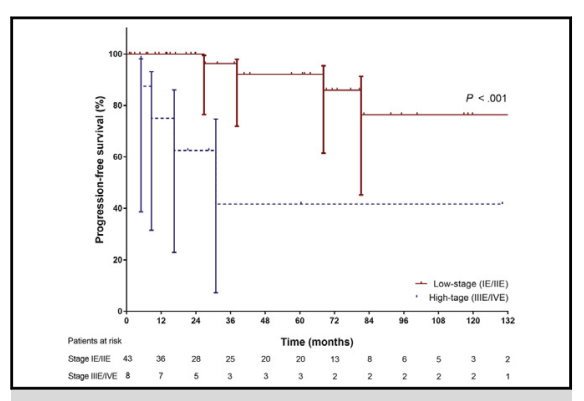

Progression-free survival of pulmonary MALT lymphoma by stage.

\section{Central Message}

The clinical course of low-stage (IE/IIE) pulmonary mucosa-associated lymphoid tissue lymphoma, for which the mainstay of treatment is surgical resection, is indolent.

\section{Perspective}

In this study, the mainstays of treatment for low-stage (IE/IIE) and high-stage (IIIE/IVE) pulmonary mucosa-associated lymphoid (MALT) lymphoma were surgical resection and chemotherapy, respectively. Low-stage lymphoma was associated with longer progression-free survival, suggesting that complete surgical resection may afford favorable treatment outcomes for low-stage pulmonary MALT lymphomas.

See Editorial Commentary page 350.
From the a Division of Pulmonology and Critical Care Medicine, Department of Medicine, Departments of ${ }^{\mathrm{b}}$ Internal Medicine, ${ }^{\mathrm{c}}$ Radiology, and ${ }^{\mathrm{d}}$ Thoracic and Cardiovascular Surgery, Samsung Medical Center, Sungkyunkwan University School of Medicine, Seoul, Korea.

H.L. and B.Y. contributed equally to this work.

Received for publication July 10, 2016; revisions received Feb 10, 2017; accepted for publication March 5, 2017; available ahead of print April 27, 2017.

Address for reprints: Hojoong Kim, MD, PhD, Division of Pulmonary and Critical Care Medicine, Department of Medicine, Samsung Medical Center, Sungkyunkwan University School of Medicine, 81 Irwon-ro, Gangnam-gu, Seoul 06351, Korea (E-mail: hjk3425@skku.edu).

$0022-5223 / \$ 36.00$

Copyright (c) 2017 by The American Association for Thoracic Surgery

http://dx.doi.org/10.1016/j.jtcvs.2017.03.043
Primary non-Hodgkin lymphomas of the lung are very rare, composing only $0.5 \%$ to $1.0 \%$ of all lung malignancies ${ }^{1}$ and only $0.4 \%$ of all lymphomas. ${ }^{2}$ The most common primary lymphoma of the lung is low-grade marginal zone

Scanning this QR code will take you to a supplemental video for the article. 


\section{Abbreviations and Acronyms \\ CT = computed tomography \\ $\mathrm{IQR}=$ interquartile range \\ MALT $=$ mucosa-associated lymphoid tissue \\ PFS = progression-free survival}

B-cell lymphoma of mucosa-associated lymphoid tissue (MALT), ${ }^{1-4}$ which arises from bronchial-associated lymphoid tissue. ${ }^{5,6}$

Pulmonary MALT lymphoma is indolent and progresses more slowly than other malignant lymphomas. ${ }^{1-4,7-19}$ Currently available treatments include surgical resection, chemotherapy, immunotherapy, radiotherapy, and observation $^{1-3,7-20}$; however, the optimal treatment remains to be defined, with no relevant randomized controlled trials reported to date. ${ }^{1-3,7-19}$ Unfortunately, the low prevalence and indolent clinical course of pulmonary MALT lymphoma makes it difficult to perform a randomized controlled trial comparing treatment modalities. Nevertheless, surgical resection is considered a useful initial treatment option when the lesion is localized; previous studies have reported favorable outcomes (with a high complete resection rate without subsequent disease recurrence) following surgical resection in patients with pulmonary MALT lymphoma. ${ }^{1-3,7-10}$ Because most patients (up to approximately $85 \%$ ) are diagnosed at an early disease stage (stage IE or IIE), studies seeking optimal treatment modalities for these patients are needed.

It was recently suggested that limited resection of the lung might be a useful alternative to lobectomy when managing patients with small, early-stage non-small cell lung cancers. ${ }^{21-24}$ Considering the indolent characteristics of pulmonary MALT lymphoma and the advantages of limited resection compared with lobectomy in preserving lung function and reducing postsurgical pulmonary complications, a similar strategy could be adopted to treat peripherally localized stage IE pulmonary MALT lymphomas. However, no study has yet evaluated treatment outcomes after limited resection of pulmonary MALT lymphomas in patients with peripherally localized lesions.

In the present study, we evaluated the clinical characteristics of, treatment modalities prescribed for, and treatment outcomes of patients with pulmonary MALT lymphoma by stage strata. We also evaluated the outcomes after limited resection of peripherally localized stage IE pulmonary MALT lymphoma.

\section{METHODS}

\section{Patients}

The medical records of 51 patients diagnosed with pulmonary MALT lymphoma in Samsung Medical Center (a 1979-bed referral

\begin{tabular}{ll} 
Stage & Description \\
\hline IE & Unilateral or bilateral presentation of the lung \\
IIE & $\begin{array}{l}\text { Lung presentation with hilar (II 1E) or mediastinal lymph node (II 2E) or } \\
\text { chest wall or diaphragm involvement (II 2EW) }\end{array}$ \\
IIIE & Lung presentation with abdominal lymph node involvement \\
IVE & Lung presentation with extra-lymphatic organs or tissue involvement
\end{tabular}

FIGURE 1. Modified Ann Arbor staging.

hospital in Seoul, Korea) between January 2003 and December 2015 were reviewed retrospectively. All patients were pathologically diagnosed with pulmonary MALT lymphoma; biopsy specimens were obtained via video-assisted thoracoscopic surgery (VATS) wedge resection $(\mathrm{n}=38 ; 74.5 \%)$, transbronchial lung biopsy $(\mathrm{n}=6$; $11.8 \%)$, core needle biopsy $(n=6 ; 11.8 \%)$, and percutaneous needle aspiration $(\mathrm{n}=1 ; 1.9 \%)$. The study was approved by the Institutional Review Board of Samsung Medical Center. Because of the study's retrospective nature, the need for written patient consent was waived (IRB no. 2016-04-111).

\section{Initial Diagnosis and Staging of Pulmonary MALT Lymphoma}

Staging was performed using modified Ann Arbor staging; anatomic staging was used for patients undergoing curative surgical resection. Otherwise, patients were clinically staged (Figure 1 ). ${ }^{2}$ Initial pulmonary MALT lymphoma staging featured the following evaluations: comprehensive medical history, physical examination, and radiologic imaging, including computed tomography (CT) scans of the chest and abdomen and positron emission tomography/CT. Radiologic findings were classified as one of the following patterns according to the pattern and distribution of lung lesions: (1) single nodular or consolidation pattern, (2) multiple nodular or consolidation pattern, (3) bronchiectasis and bronchiolitis pattern, or (4) diffuse interstitial lung disease pattern. ${ }^{25}$ Tumor locations in CT scans were defined as follows: tumors not involving the lobes or more proximal airway and surrounded by lung parenchyma were classified as peripheral, and all others were classified as central. ${ }^{26}$ Brain magnetic resonance imaging or bone marrow biopsy was performed in selected patients at the attending physician's clinical discretion.

\section{Treatment and Response Criteria}

Patients with pulmonary MALT lymphoma were managed by a multidisciplinary team comprising several specialists, including a pulmonologist, thoracic surgeon, radiologist, and oncologist. In general, the patients were treated with respect to stage. Patients with stage IE pulmonary MALT lymphoma with unilateral pulmonary involvement were treated by surgical resection or simple follow-up (ie, without any treatment). In cases where the tumors were completely resected, no adjuvant treatment was provided. In contrast, patients with stage IE pulmonary MALT lymphoma with bilateral pulmonary involvement or multifocal lesions underwent surgical resection, received chemotherapy, or were followed-up without treatment. Patients with stage IIE pulmonary MALT lymphoma underwent surgical resection if the pulmonary lesions and mediastinal lymph nodes were completely resectable; if surgical resection was not possible, the patients received chemotherapy or were closely followed without treatment. Patients with stage IIIE or IVE disease were treated principally with chemotherapy.

Following initial treatment, the patients were followed up with chest CT scans, abdominal CT scans (for patients with stage IIIE/IVE disease), and laboratory studies at 3-month intervals during the first year of follow-up and at 6-month intervals thereafter. The responses seen on CT scans were categorized based on the literature as complete response, partial response, stable disease, or progressive disease. ${ }^{27}$ In patients undergoing curative surgical resection, response was categorized as complete response 
(ie, no evidence of recurrence) or progressive disease (ie, recurrence or new pulmonary and extrapulmonary lesions [nodes and extranodal sites other than lung]); otherwise, response was categorized as complete response (ie, disappearance of all lymphoma imaging on CT scans and all nodes $\leq 1.5 \mathrm{~cm}$ in longest diameter), partial response (ie, $\geq 50 \%$ reduction in the sum of the products of the perpendicular diameters of up to 6 dominant pulmonary and extrapulmonary lesions for multiple lesions, or $\geq 50 \%$ reduction in the product of the perpendicular diameter for a single lesion), stable disease (ie, $<50 \%$ reduction from baseline in the sum of the products of the perpendicular diameters of pulmonary and extrapulmonary lesions, including nodes and extranodal sites, and no criteria met for progressive disease), or progressive disease (ie, $\geq 50 \%$ increase from baseline in the sum of the products of the perpendicular diameters of any previously identified abnormal pulmonary and extrapulmonary lesions, or the appearance of new lesions).

Patients with disease progression were generally treated as follows. Surgical resection was performed for patients with completely resectable tumors, and second-line chemotherapy was provided to patients who progressed following initial chemotherapy. Progression-free survival (PFS) was defined as the time from the date of treatment initiation to the date of progression in patients who received treatment or as the time from the date of the decision to watch and wait to the date of progression in patients who received simple follow-up without any treatment.

\section{Statistical Analyses}

Continuous variables are described as median with interquartile range (IQR), and categorical variables are reported number and percentage. Continuous variables were compared using the Mann-Whitney $U$ test, and categorical variables were compared using the $\chi^{2}$ test with Yates continuity correction. Clinical presentations were evaluated by stage strata (from IE to IVE). The Cochran-Armitage test was used to evaluate the associations between the proportions of patients with respiratory symptoms, B symptoms, and higher International Prognostic Index (IPI) scores (2-3) and an increase in stage. To compare treatment modalities and treatment outcomes, patients were further stratified by low-stage (IE/IIE) versus high-stage (IIIE/IVE). PFS was estimated by the Kaplan-Meier method, and the distribution of survival over time between low-stage and highstage patients was compared using the log-rank test. A Cox proportional hazard model was used to determine whether a high stage was associated with reduced PFS. The initial clinical variables entered into the model included age, sex, performance status, and modified Ann Arbor stage. A stepwise backward selection method, with elimination of variables exhibiting a $P$ value $>.20$ in univariable analyses, was used to identify clinical variables for inclusion in the final model. A 2 -sided $P$ value $<.05$ was considered to reflect statistical significance. All statistical analyses were performed using R version 3.2.3 (R Foundation for Statistical Computing, Vienna, Austria).

TABLE 1. Clinical characteristics of patients with pulmonary MALT lymphoma by stage strata

\begin{tabular}{|c|c|c|c|c|c|c|}
\hline \multirow[b]{2}{*}{ Characteristic } & \multirow[b]{2}{*}{ Total $(\mathbf{n}=\mathbf{5 1})$} & \multicolumn{2}{|c|}{ Low-stage } & \multicolumn{2}{|c|}{ High-stage } & \multirow[b]{2}{*}{$P$ value } \\
\hline & & Stage IE $(n=39)$ & Stage IIE $(n=4)$ & Stage IIIE $(n=3)$ & Stage IVE $(n=5)$ & \\
\hline Age, y, median (IQR) & $54(49-60)$ & $54(50-61)$ & $55(42-62)$ & $48(41-52)$ & $58(54-59)$ & .575 \\
\hline Male sex, $\mathrm{n}(\%)$ & $27(52.9)$ & $21(53.8)$ & $4(100)$ & $1(33.3)$ & $1(20.0)$ & .102 \\
\hline Never smoker, n (\%) & $33(64.7)$ & $24(61.5)$ & $4(100)$ & $2(66.7)$ & $3(60.0)$ & .492 \\
\hline \multicolumn{7}{|l|}{ Comorbidities, n (\%) } \\
\hline Chronic pulmonary disease & $12(23.5)$ & $8(20.5)$ & $0(0)$ & $2(66.7)$ & $2(40.0)$ & .152 \\
\hline Hypertension & $10(19.6)$ & $9(23.1)$ & $0(0)$ & $1(33.3)$ & $0(0)$ & .415 \\
\hline Previous malignancy & $8(15.7)$ & $7(17.9)$ & $1(25.0)$ & $0(0)$ & $0(0)$ & .593 \\
\hline Autoimmune disease & $7(13.7)$ & $4(10.3)$ & $2(50.0)$ & $1(33.3)$ & $0(0)$ & .085 \\
\hline Diabetes mellitus & $3(5.9)$ & $3(7.7)$ & $0(0)$ & $0(0)$ & $0(0)$ & .806 \\
\hline \multicolumn{7}{|l|}{ Respiratory symptoms, n (\%) } \\
\hline Cough & $30(58.8)$ & $18(46.2)$ & $4(100)$ & $3(100)$ & $5(100)$ & $.003^{*}$ \\
\hline Sputum & $19(37.3)$ & $11(28.2)$ & $2(50.0)$ & $3(100)$ & $3(60.0)$ & $.023^{*}$ \\
\hline Dyspnea & $4(7.8)$ & $1(2.6)$ & $1(25.0)$ & $1(33.3)$ & $1(20.0)$ & $.031^{*}$ \\
\hline Hemoptysis & $3(5.9)$ & $1(2.6)$ & $0(0.0)$ & $1(33.3)$ & $1(20.0)$ & $.032 *$ \\
\hline B symptoms, n (\%) & 9 (17.6) & $1(2.6)$ & $1(25.0)$ & $3(100)$ & $4(80.0)$ & $<.001 *$ \\
\hline Performance status, n (\%) & & & & & & .533 \\
\hline 0 & $41(80.4)$ & $32(82.1)$ & $3(75.0)$ & $3(100)$ & $3(60.0)$ & \\
\hline 1 & $10(19.6)$ & $7(17.9)$ & $1(25.0)$ & $0(0)$ & $2(40.0)$ & \\
\hline Radiologic findings, $\mathrm{n}(\%)$ & & & & & & .153 \\
\hline Single nodular or consolidation & $28(54.9)$ & $24(61.5)$ & $2(50.0)$ & $1(33.3)$ & $1(20.0)$ & \\
\hline Multiple nodular or consolidation & $14(27.5)$ & $9(23.1)$ & $2(50.0)$ & $2(66.7)$ & $1(20.0)$ & \\
\hline Bronchiectasis and bronchiolitis & $5(9.8)$ & $4(10.3)$ & $0(0)$ & $0(0)$ & $1(20.0)$ & \\
\hline Diffuse interstitial lung disease & $4(7.8)$ & $2(5.1)$ & $0(0)$ & $0(0)$ & $2(40.0)$ & \\
\hline Diagnostic method, n (\%) & & & & & & .037 \\
\hline Percutaneous needle aspiration/biopsy & $7(13.7)$ & $3(7.7)$ & $0(0.0)$ & $1(33.3)$ & $3(60.0)$ & \\
\hline Transbronchial lung biopsy & $6(11.8)$ & $4(10.2)$ & $1(25.0)$ & $1(33.3)$ & $0(0)$ & \\
\hline VATS wedge resection & $38(74.5)$ & $32(82.1)$ & $3(75.0)$ & $1(33.3)$ & $2(40.0)$ & \\
\hline IPI score, $\mathrm{n}(\%)$ & & & & & & $<.001 *$ \\
\hline $0-1$ & $38(74.5)$ & $34(87.2)$ & $3(75.0)$ & $1(33.3)$ & $0(0)$ & \\
\hline $2-3$ & $13(25.5)$ & $5(12.8)$ & $1(25.0)$ & $2(66.7)$ & $5(100)$ & \\
\hline
\end{tabular}

$I Q R$, Interquartile range; VATS, video-assisted thoracoscopic surgery; IPI, International Prognostic Index. ${ }^{*} P$ value for trend test. 


\section{RESULTS \\ Patients}

The baseline characteristics of 51 patients with pulmonary MALT lymphoma are summarized by stage strata in Table 1. Using the modified Ann Arbor staging system, patients were stratified into 2 groups: low-stage (stage IE/IIE; $\mathrm{n}=43 ; 39$ and 4 , respectively) and high-stage (stage IIIE/ IVE; $\mathrm{n}=8 ; 3$ and 5 , respectively). There were no significant between-group differences in the clinical factors, including age, sex, smoking history, comorbidities, radiologic findings, or performance status across the stages. However, the proportion of patients with respiratory and B symptoms and a high IPI score (2-3) increased with advancing stage $\left(P_{\text {trend }}=.003\right.$ for cough, .023 for sputum, .031 for dyspnea, .032 for hemoptysis, $<.001$ for B symptoms, and $<.001$ for high IPI score).

Regarding diagnostic methods, more than $75 \%$ of lowstage patients underwent VATS wedge resection $(82.1 \%$ for stage IE and $75 \%$ for stage IIE) for the diagnosis of pulmonary MALT lymphoma. For the high-stage patients, various diagnostic methods were used.

\section{Treatment Modalities and Treatment Responses in Patients With Pulmonary MALT Lymphoma}

As shown in Table 2, patients with low-stage disease were more likely to undergo surgical resection $(76.7 \%$ [33 of 43] vs $0 \%$ [0 of 8]; $P<.001$ ), whereas patients with high-stage disease were more likely to receive systemic chemotherapy $(87.5 \%$ [7 of 8 ] vs $14.0 \%$ [6 of 43]; $P<.001)$. There was no significant difference in the median duration of follow-up between patients with low-stage and high-stage disease (40.7 months [IQR, 16.0-79.1 months] vs 35.9 months [IQR, 22.461.2 months]; $P=.990$ ). During the follow-up period, the proportion of patients remaining in complete response was higher in the low-stage disease group $(81.4 \%$ [35 of
43] vs $25.0 \%$ [ 2 of 8 ]; $P=.004)$, but the proportion of patients developing progressive disease was higher in the high-stage disease group $(50 \%$ [ 4 of 8 ] vs $7.0 \%$ [3 of 43]; $P=.007$ ).

As shown in Figure 2, PFS was significantly longer in the low-stage disease group (median, 24.9 months [IQR, 12.645.6 months] vs 40.7 months [IQR, 16.0-75.2 months]; $P<.001)$. Patients in the high-stage disease group were 9.2 times more likely to progress when adjusted for other clinical variables (hazard ratio, 9.24; 95\% confidence interval, 1.93-44.36) (Table 3).

\section{Treatment Responses in Patients Who Underwent Surgical Resection and Those Who Did Not Undergo Surgical Resection Among Patients With Low-Stage Pulmonary MALT Lymphoma}

Of the 43 patients with low-stage pulmonary MALT lymphoma, 33 underwent complete surgical resection, and the other 10 did not undergo surgery (systemic chemotherapy, $\mathrm{n}=6$; watch and wait, $\mathrm{n}=4$ ). Among the 33 patients who underwent surgical resection, $32(97 \%)$ remained in complete remission and $1(3 \%)$ developed progressive disease. In comparison, among the 10 patients who did not undergo surgical resection, 3 remained in complete remission, 3 remained in stable disease, 2 had partial response, and 2 developed progressive disease ( 1 of whom died of sepsis during second-line chemotherapy for progressive disease). Although the proportion of patients who remained in complete remission was significantly higher in patients who underwent surgical resection compared with those who did not (97.0\% [ 32 of 33 ] vs $30.0 \%$ [ 3 of 10 ]; $P<.001$ ), there was no significant difference between the 2 groups in the proportion of patients who developed progressive disease $(3.0 \%$ [ 1 of 33 ] vs $20.0 \%$ [ 2 of 10 ]; $P=.256$ ). In survival analysis, there was also no significant difference in PFS between the patients who underwent surgical resection and those who $\operatorname{did} \operatorname{not}(P=.319)$.

TABLE 2. Treatment modalities and treatment responses in patients with low-stage and high-stage pulmonary MALT lymphoma

\begin{tabular}{|c|c|c|c|}
\hline Variable & Low-stage $($ IE/IIE) $(n=43)$ & High-stage (IIIE/IVE) $(n=8)$ & $P$ value \\
\hline Treatment, n (\%) & & & $<.001$ \\
\hline Surgical resection & $33(76.7)$ & $0(0)$ & \\
\hline Systemic chemotherapy & $6(14.0)$ & $7(87.5)$ & \\
\hline Watch-and-wait & $4(9.3)$ & $1(12.5)$ & \\
\hline \multicolumn{4}{|l|}{ Treatment response, $\mathrm{n}(\%)$} \\
\hline Complete response & $35(81.4)$ & $2(25.0)$ & .004 \\
\hline Partial response or stable disease & $5(11.6)$ & $2(25.0)$ & .653 \\
\hline Progressive disease & $3(7.0)^{*}$ & $4(50.0)$ & .007 \\
\hline Death & $1(2.3)^{*}$ & $0(0)$ & 1.0 \\
\hline Follow-up duration, mo, median (IQR) & $40.7(16.0-79.1)$ & $35.9(22.4-61.2)$ & .990 \\
\hline Time to progression, mo, median (IQR) & $59.7(38.2-81.2)$ & $12.6(6.8-23.7)$ & .064 \\
\hline
\end{tabular}

$I Q R$, Interquartile range. *Among 3 patients with low-stage MALT lymphoma who had progressive disease, 1 died of sepsis during second-line chemotherapy for progressive disease. 


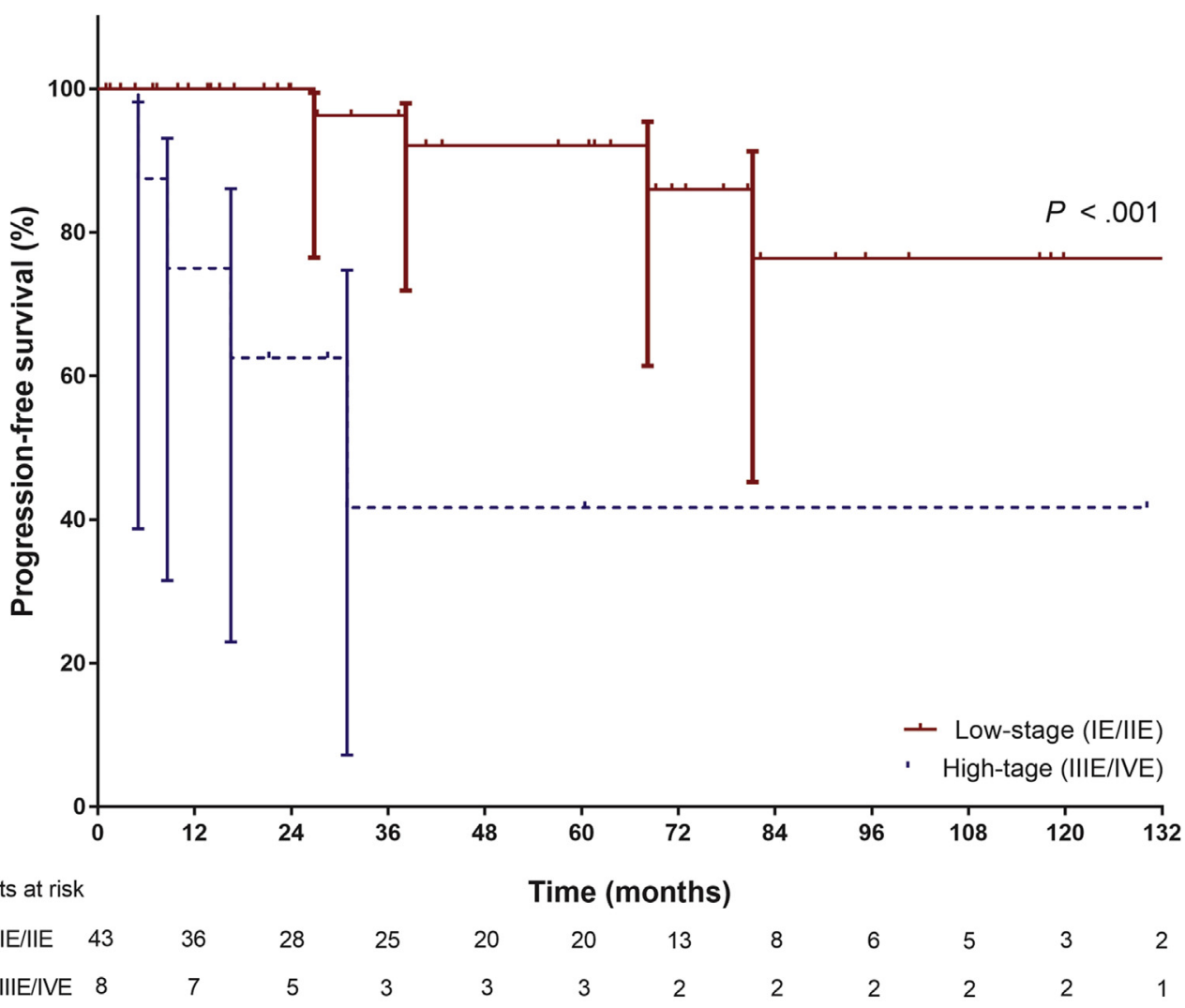

FIGURE 2. Progression-free survival of patients with stage IE/IIE and stage IIIE/IVE pulmonary MALT lymphoma.

\section{Surgical Treatments and Treatment Responses in Patients With Stage IE Pulmonary MALT \\ Lymphoma}

Of 39 patients with stage IE pulmonary MALT lymphoma, $30(76.9 \%)$ underwent surgical resection, including 8 with central tumors and 22 with peripheral tumors. Regarding surgical type, all patients with central tumors were treated by VATS lobectomy. In comparison, approximately one-third of patients with peripheral tumors $(36.4 \% ; 8$ of 22$)$ were treated via VATS lobectomy, and the remaining patients $(63.6 \% ; 14$ of 22$)$ were treated by limited resection, including VATS wedge resection (Video 1) $(\mathrm{n}=13)$ and VATS segmentectomy $(\mathrm{n}=1)$. One of the 8 patients with central tumors experienced recurrence and subsequently underwent VATS lobectomy. However, all 22 patients with peripheral tumors remained in complete response, without progressive disease (Table 4).

Regarding postoperative complications, no complications developed after surgery in patients who underwent limited resection, whereas postoperative complications

TABLE 3. Results of the univariable and multivariable Cox proportional hazard model of disease progression in patients with pulmonary MALT lymphoma

\begin{tabular}{|c|c|c|c|c|}
\hline \multirow[b]{2}{*}{ Variable } & \multicolumn{2}{|c|}{ Univariable analysis } & \multicolumn{2}{|c|}{ Multivariable analysis } \\
\hline & HR & $P$ value & Adjusted HR & $95 \%$ CI \\
\hline Age & 1.03 & .426 & & \\
\hline Male sex & 5.98 & .038 & 6.05 & $0.93-39.57$ \\
\hline \multicolumn{5}{|l|}{ Modified Ann Arbor stage } \\
\hline Low-stage (stage IE/IIE) & Reference & & Reference & \\
\hline High-stage (stage IIIE/IVE) & 7.66 & .005 & 9.24 & $1.93-44.36$ \\
\hline \multicolumn{5}{|l|}{ Performance status } \\
\hline 0 & Reference & & Reference & \\
\hline 1 & 2.84 & .155 & 4.03 & $0.34-19.45$ \\
\hline
\end{tabular}




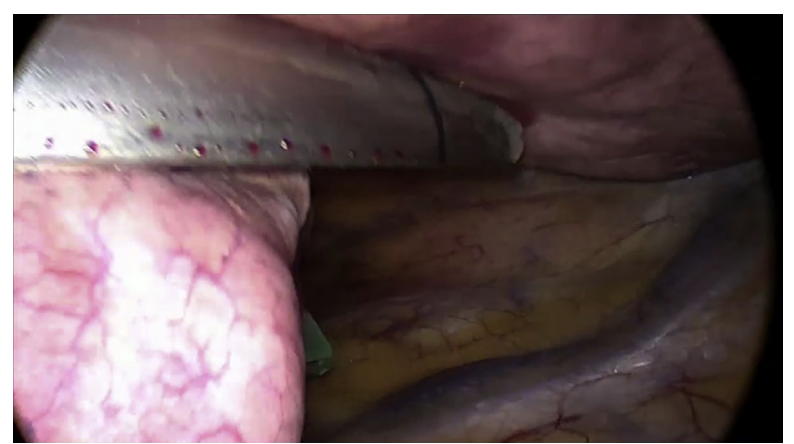

VIDEO 1. VATS wedge resection for the treatment of localized pulmonary MALT lymphoma. Video available at: http://www.jtcvsonline.org/ article/S0022-5223(17)30547-0/addons.

occurred in 2 patients who underwent lobectomy (chylothorax in one with a peripheral tumor and prolonged pneumothorax attributable to an air leak in the other with a central tumor).

\section{DISCUSSION}

Our evaluation of the clinical presentations, treatment outcomes, and prognoses of 51 patients with pulmonary MALT lymphoma shows that pulmonary MALT lymphoma is indolent and associated with favorable outcomes, but disease progression increases significantly as with advancing disease stage. Moreover, limited resection may be an effective treatment modality for the management of peripherally localized stage IE pulmonary MALT lymphoma. To the best of our knowledge, this is the first study to describe the treatment outcomes of limited surgical resection for peripherally localized pulmonary MALT lymphoma.

In agreement with the results of previous studies, ${ }^{1-3,7-18}$ the presentation and clinical course of pulmonary MALT lymphoma was indolent. In terms of staging, most patients $(86 \%)$ were diagnosed with early-stage disease (ie, stage IE/IIE). A previous study found that $86 \%$ of patients with pulmonary MALT lymphoma were in stage I/II at the time of diagnosis. ${ }^{7}$ Another study found that approximately $50 \%$ of patients were in stage I at the time of initial diagnosis. ${ }^{8}$ Because most patients are diagnosed early, the proportion of patients with symptoms is relatively low. In the present study, approximately two-thirds of patients had a cough, and one-third had sputum production. In previous studies, approximately one-half to two-thirds of patients had respiratory symptoms., , $^{3,8,16}$ Constitutional symptoms were even less common. ${ }^{3,7,8}$ Only $18 \%$ of patients in the present study had B symptoms, and previous studies have reported constitutional symptoms in $15 \%$ to $43 \%$ of patients ${ }^{7,8,13,18}$; however, the proportion of patients with symptoms increased with advancing disease stage. Among patients with stage III/IV pulmonary MALT lymphoma, cough and sputum production were evident in $100 \%$ and $75 \%$, respectively, and $\mathrm{B}$ symptoms were present in $88 \%$. Given that previous studies did not compare clinical symptoms with respect to stage, our present work is informative in that it shows a close relationship between symptoms and stage. In line with previously reported findings, ${ }^{1-3,7-18}$ the

TABLE 4. Clinical characteristics and treatment outcomes in patients with stage IE pulmonary MALT lymphoma who underwent surgical resection

\begin{tabular}{|c|c|c|c|}
\hline Variable & Central tumor $(n=8)$ & Peripheral tumor $(n=22)$ & $P$ value \\
\hline Age, y, median (IQR) & $58(53-61)$ & $52(47-58)$ & .279 \\
\hline Female sex, n (\%) & $4(50.0)$ & $12(54.5)$ & 1.0 \\
\hline \multicolumn{4}{|l|}{ Radiologic findings } \\
\hline Longest diameter, $\mathrm{cm}$, median (IQR) & $28.0(20.5-34.5)$ & $21.0(16.0-28.0)$ & .204 \\
\hline Classification, n (\%) & & & .281 \\
\hline Single nodular or consolidation & $7(87.5)$ & $16(72.7)$ & \\
\hline Multiple nodular or consolidation & $0(0)$ & $5(22.7)$ & \\
\hline Bronchiectasis and bronchiolitis & $1(12.5)$ & $1(4.5)$ & \\
\hline Diagnostic methods, $\mathrm{n}(\%)$ & & & $<.001$ \\
\hline Percutaneous needle biopsy & $2(25.0)$ & $0(0)$ & \\
\hline Transbronchial biopsy & $3(37.5)$ & $0(0)$ & \\
\hline VATS wedge resection & $3(37.5)$ & $22(100)$ & \\
\hline \multicolumn{4}{|l|}{ Treatment characteristics, $\mathrm{n}(\%)$} \\
\hline Surgical treatment & & & .007 \\
\hline VATS, lobectomy & $8(100)^{*}$ & $8(36.4) \dagger$ & \\
\hline VATS, limited resection & $0(0)$ & $14(63.6)$ & \\
\hline Complications & $1(12.5)^{*}$ & $1(4.5) \dagger$ & 1.0 \\
\hline \multicolumn{4}{|l|}{ Treatment outcome } \\
\hline Progressive disease, $\mathrm{n}(\%)$ & $1(12.5)$ & $0(0)$ & .591 \\
\hline Follow-up duration, mo, median (IQR) & $62.2(39.5-81.4)$ & $22.1(9.9-69.2)$ & .039 \\
\hline
\end{tabular}

$I Q R$, Interquartile range; VATS, video-assisted thoracoscopic surgery. *Prolonged pneumothorax attributable to an air leak. $\dagger$ Chylothorax. 
prognosis of patients with pulmonary MALT lymphoma was relatively good. Over a median follow-up of 40.7 months, 7 patients $(14 \%)$ developed progressive disease and 1 patient died of septic shock that developed during second-line chemotherapy to treat progressive disease. Following first-line chemotherapy to treat the pulmonary MALT lymphoma, the patient remained in stable disease for 68.2 months. Similar to the favorable treatment outcomes reported by previous studies, ${ }^{7,8}$ we found no significant difference in overall survival rate between patients with stage IE/IIE disease and those with stage IIIE/IVE disease. However, PFS was significantly longer in patients with stage IE/IIE disease, reflecting the slowly progressive nature of pulmonary MALT lymphoma.

Two opposing opinions have been expressed in the context of surgical resection of pulmonary MALT lymphoma with localized lesions. Some experts have suggested that surgery (owing to its associated risks) should not be the first choice of treatment, the aim of which should be to preserve lung function. ${ }^{12,13,15,16} \mathrm{Oh}$ et $\mathrm{al}^{16}$ found no differences in overall survival between patients given chemotherapy and those who underwent surgery. In an evaluation of treatment outcomes in 17 patients with pulmonary MALT lymphoma (15 with stage IE and 2 with stage IV disease) treated with a fludarabine- and mitoxantronecontaining regimen, Zinzani et $\mathrm{al}^{18}$ found that $82 \%$ achieved complete response. More recently, Wang et $\mathrm{al}^{13}$ reported that chemotherapy provided longer PFS compared with radical surgical resection, despite no differences in overall survival, in patients with early pulmonary MALT lymphoma.

On the other hand, others consider surgical resection the treatment of choice, especially in young patients with pulmonary MALT lymphoma limited to one side of the lung. ${ }^{1,2,7,8,10,14}$ Numerous studies have shown that complete surgical resection is associated with prolonged complete response. , $^{2,8,10,14,19}$ In support of this latter position, we found that most patients who underwent surgical treatment did not develop progressive disease. Extending the findings of previous studies, we also found that limited resection for peripherally located tumors afforded favorable treatment outcomes. Moreover, no postoperative complication developed after limited resection, whereas 1 patient developed complication following lobectomy. Our results thus strongly suggest that peripherally localized stage IE pulmonary MALT lymphoma can be successfully managed by limited resection with maintenance of the advantage (complete response) afforded by lobectomy. To the best of our knowledge, this is the first study to evaluate the clinical implications and treatment outcomes of limited resection in patients with pulmonary MALT lymphoma.

This study has several limitations. First, the study was retrospective in nature and confined to a single center.
Second, the relatively small number of patients might have led to errors in the multivariable analyses. In addition, the lack of significance has a high likelihood of being a type II error in most of the subset analyses. Third, although we showed that limited resection may be a useful treatment in select patients with peripherally localized stage-IE pulmonary MALT lymphoma, we could not compare the treatment outcomes of limited resection versus lobectomy owing to the small number of patients. In addition, we also could not compare the treatment outcomes of surgical resection with those of such treatment modalities as watchful observation, immunotherapy, chemotherapy, and radiotherapy. Interestingly, Wang et $\mathrm{al}^{13}$ also reported that radical surgical resection might not be the of treatment choice for early pulmonary MALT lymphoma. In that study, chemotherapy provided superior treatment outcomes compared with radical surgical resection. However, it should be emphasized that surgical resection is often necessary to confirm the diagnosis of pulmonary MALT lymphoma (especially for peripherally localized tumors) given the lack of definitive findings compatible with pulmonary MALT lymphoma, although single or multiple nodules or areas of consolidation that are indolent on serial CT scans are suggestive of the disease. ${ }^{25}$ Therefore, we suggest that surgical resection may be the treatment of choice for patients with localized lesions suspicious for pulmonary MALT lymphoma. In such cases, surgical resection allows for not only accurate diagnosis, but also successful management (thus with a high probability of complete response).

In conclusion, our findings demonstrate pulmonary MALT lymphoma, for which the majority of low-stage patients are treated via surgical resection and high-stage patients are treated with chemotherapy, has indolent and favorable treatment outcomes. Low-stage pulmonary MALT lymphoma exhibited longer PFS, which suggests that complete surgical resection may afford favorable treatment outcomes. However, future studies with larger numbers of patients are needed to fully evaluate the role of surgical resection in the treatment of low-stage pulmonary MALT lymphoma.

\section{Conflict of Interest Statement}

Authors have nothing to disclose with regard to commercial support.

\footnotetext{
References

1. Borie R, Wislez M, Antoine M, Copie-Bergman C, Thieblemont C, Cadranel J. Pulmonary mucosa-associated lymphoid tissue lymphoma revisited. Eur Respir J. 2016;47:1244-60.

2. Ferraro P, Trastek VF, Adlakha H, Deschamps C, Allen MS, Pairolero PC. Primary non-Hodgkin's lymphoma of the lung. Ann Thorac Surg. 2000;69:993-7.

3. Borie R, Wislez M, Thabut G, Antoine M, Rabbat A, Couderc LJ, et al. Clinical characteristics and prognostic factors of pulmonary MALT lymphoma. Eur Respir J. 2009;34:1408-16.
} 
4. Li G, Hansmann ML, Zwingers T, Lennert K. Primary lymphomas of the lung: morphological, immunohistochemical and clinical features. Histopathology. 1990;16:519-31.

5. Isaacson P, Wright DH. Extranodal malignant lymphoma arising from mucosaassociated lymphoid tissue. Cancer. 1984;53:2515-24.

6. Harris NL, Jaffe ES, Stein H, Banks PM, Chan JK, Cleary ML, et al. A revised European-American classification of lymphoid neoplasms: a proposal from the International Lymphoma Study Group. Blood. 1994;84:1361-92.

7. Sammassimo S, Pruneri G, Andreola G, Montoro J, Steffanoni S, Nowakowski GS, et al. A retrospective international study on primary extranodal marginal zone lymphoma of the lung (BALT lymphoma) on behalf of International Extranodal Lymphoma Study Group (IELSG). Hematol Oncol. 2016;34: 177-83.

8. Stefanovic A, Morgensztern D, Fong T, Lossos IS. Pulmonary marginal zone lymphoma: a single centre experience and review of the SEER database. Leuk Lymphoma. 2008;49:1311-20.

9. Cadranel J, Wislez M, Antoine M. Primary pulmonary lymphoma. Eur Respir J. 2002;20:750-62.

10. Ahmed S, Kussick SJ, Siddiqui AK, Bhuiya TA, Khan A, Sarewitz S, et al. Bronchial-associated lymphoid tissue lymphoma: a clinical study of a rare disease. Eur J Cancer. 2004;40:1320-6.

11. Cordier JF, Chailleux E, Lauque D, Reynaud-Gaubert M, Dietemann-Molard A, Dalphin JC, et al. Primary pulmonary lymphomas. A clinical study of 70 cases in nonimmunocompromised patients. Chest. 1993;103:201-8.

12. Girinsky T, Paumier A, Ferme C, Hanna C, Ribrag V, Leroy-Ladurie F, et al. Low-dose radiation treatment in pulmonary mucosa-associated lymphoid tissue lymphoma: a plausible approach? A single-institution experience in 10 patients. Int J Radiat Oncol Biol Phys. 2012;83:e385-9.

13. Wang L, Xia ZJ, Zhang YJ, Huang HQ, Lin TY, Lu Y. Radical surgery may be not an optimal treatment approach for pulmonary MALT lymphoma. Tumour Biol. 2015;36:6409-16.

14. Imai H, Sunaga N, Kaira K, Kawashima O, Yanagitani N, Sato K, et al. Clinicopathological features of patients with bronchial-associated lymphoid tissue lymphoma. Intern Med. 2009;48:301-6.

15. Troch M, Streubel B, Petkov V, Turetschek K, Chott A, Raderer M. Does MALT lymphoma of the lung require immediate treatment? An analysis of 11 untreated cases with long-term follow-up. Anticancer Res. 2007;27:3633-7.

16. Oh SY, Kim WS, Kim JS, Kim SJ, Kwon HC, Lee DH, et al. Pulmonary marginal zone B-cell lymphoma of MALT type-what is a prognostic factor and which is the optimal treatment, operation, or chemotherapy?: Consortium for Improving Survival of Lymphoma (CISL) study. Ann Hematol. 2010;89:563-8.

17. Kim JH, Lee SH, Park J, Kim HY, Lee SI, Park JO, et al. Primary pulmonary nonHodgkin's lymphoma. Jpn J Clin Oncol. 2004;34:510-4.
18. Zinzani PL, Pellegrini C, Gandolfi L, Casadei B, Derenzini E, Broccoli A, et al Extranodal marginal zone B-cell lymphoma of the lung: experience with fludarabine and mitoxantrone-containing regimens. Hematol Oncol. 2013;31:183-8.

19. Kennedy JL, Nathwani BN, Burke JS, Hill LR, Rappaport H. Pulmonary lym phomas and other pulmonary lymphoid lesions. A clinicopathologic and immunologic study of 64 patients. Cancer. 1985;56:539-52.

20. Zucca E, Conconi A, Laszlo D, López-Guillermo A, Bouabdallah R, Coiffier B, et al. Addition of rituximab to chlorambucil produces superior event-free survival in the treatment of patients with extranodal marginal-zone B-cell lymphoma: 5year analysis of the IELSG-19 Randomized Study. J Clin Oncol. 2013;31: 565-72.

21. Yoshida J, Ishii G, Hishida T, Aokage K, Tsuboi M, Ito H, et al. Limited resection trial for pulmonary ground-glass opacity nodules: case selection based on highresolution computed tomography-interim results. Jpn J Clin Oncol. 2015;45 677-81.

22. Tsutani Y, Miyata Y, Nakayama H, Okumura S, Adachi S, Yoshimura M, et al Oncologic outcomes of segmentectomy compared with lobectomy for clinical stage IA lung adenocarcinoma: propensity score-matched analysis in a multicenter study. J Thorac Cardiovasc Surg. 2013;146:358-64.

23. Koike T, Koike T, Yoshiya K, Tsuchida M, Toyabe S. Risk factor analysis of locoregional recurrence after sublobar resection in patients with clinical stage IA non-small cell lung cancer. J Thorac Cardiovasc Surg. 2013;146: $372-8$.

24. Mohiuddin K, Haneuse S, Sofer T, Gill R, Jaklitsch MT, Colson YL, et al. Relationship between margin distance and local recurrence among patients undergoing wedge resection for small $(\leq 2 \mathrm{~cm})$ non-small cell lung cancer. $J$ Thorac Cardiovasc Surg. 2014;147:1169-75; discussion 1175-7.

25. Bae YA, Lee KS, Han J, Ko YH, Kim BT, Chung MJ, et al. Marginal zone B-cel lymphoma of bronchus-associated lymphoid tissue: imaging findings in 21 patients. Chest. 2008;133:433-40.

26. Kinsey CM, San Jose Estépar R, Wei Y, Washko GR, Christiani DC. Regional emphysema of a non-small cell tumor is associated with larger tumors and decreased survival rates. Ann Am Thorac Soc. 2015;12:1197-205.

27. Cheson BD, Horning SJ, Coiffier B, Shipp MA, Fisher RI, Connors JM, et al. Report of an international workshop to standardize response criteria for nonHodgkin's lymphomas. NCI Sponsored International Working Group. J Clin Oncol. 1999;17:1244.

Key Words: extranodal marginal B-cell lymphoma, lung neoplasm, treatment outcome, pulmonary surgical procedures, neoplasm staging 